\title{
CAUSALITY BETWEEN EXPORTS AND ECONOMIC GROWTH IN SOUTH AFRICA: EVIDENCE FROM LINEAR AND NONLINEAR TESTS
}

\author{
Ahdi N. Ajmi \\ College of Science and Humanities in Slayel, \\ Salman bin Abdulaziz University, Kingdom of Saudi Arabia \\ Goodness C. Aye \\ Department of Economics, University of Pretoria, South Africa
}

Mehmet Balcilar

Department of Economics, Eastern Mediterranean University

Famagusta, Turkish Republic of Northern Cyprus, via Mersin 10, Turkey

Rangan Gupta*

Department of Economics, University of Pretoria, South Africa

\begin{abstract}
This paper investigates the dynamic causal link between exports and economic growth using both linear and nonlinear Granger causality tests. We use annual South African data on real exports and real gross domestic product from 1911-2011. The linear Granger causality result shows no evidence of significant causality between exports and GDP. The relevant VAR is unstable, which undermines our confidence in the causality result identified by the linear Granger causality test. Accordingly we turn to the nonlinear methods to evaluate Granger causality between exports and GDP. First, we use Hiemstra and Jones (1994) nonlinear Granger causality test and find a unidirectional causality from GDP to exports. However, using a more powerful and less biased nonlinear test, the Diks and Panchenko (2006) test, we find evidence of significant bi-directional causality. These results highlight the risk of misleading conclusions based on the standard linear Granger causality tests which neither accounts for structural breaks nor uncover nonlinearities in the dynamic relationship between exports and GDP.
\end{abstract}

JEL Classifications: C14, C32, F43, O40

Keywords: Exports, Economic growth, causality, linear, nonlinear

Corresponding Authors Email Address: Rangan.Gupta@up.ac.za 


\section{INTRODUCTION}

Trade liberalisation had become conventional by the late 1980 s and was included in Williamson's (1990) "Washington consensus" of policies over which there was, at the time, little cause for disagreement. Policy makers in South Africa moved in the same direction once the normalisation of the domestic economy started in 1990, which allowed a gradual re-integration of the economy with the rest of the world. The South African government signed the Uruguay round of the General Agreement of Tariffs and Trade (GATT) and took steps to liberalise the economy, with the expectation that an outward orientation would support a higher long-run rate of economic growth (De Wet, 1995).

This paper examines the causal link between exports and real gross domestic product (GDP) in South Africa over a long-horizon using 101 years of annual data, covering the period of 1911-2011. If exports are causally linked to real GDP then important policy and development consequences follow: for example, if exports cause economic growth, then the expansion of exports may lead to the achievement of a certain degree of development for the country.

Economists have studied the relationship between international trade and output growth since Adam Smith in the second half of the eighteenth century (Medina-Smith, 2001). Though the subsequent literature is vast, it is possible to identify two main competing hypotheses, namely the "exports-led growth" (ELG) hypothesis and the "growth-led-exports" (GLE) hypothesis. The former starts with the postulate that, as a component part of GDP, exports would have a direct causal impact on GDP (Little et al., 1970; Krueger, 1978; Balassa, 1978, 1985; Singer and Gray, 1988; Greenaway and Sapsford, 1994). The literature has also suggested a number of additional channels along which exports might contribute indirectly to economic growth, through a number of channels as indicated by Balcilar and Ozdemir (2013). First, exporters in countries with limited home markets have the chance to gain efficiency from economies of scale via the exports market (Helpman and Krugman, 1985). Second, exports open the way for increased imports, including productivity enhancing capital goods, by easing foreign exchange constraints (McKinnon, 1964; Chenery and Strout, 1966). Third, the exposure to international competition creates pressure for more efficient production in the home economy too (Balassa, 1978; Bhagwati and Srinivasan, 1979; Krueger, 1980). Fourth, international trade is an important vehicle for the transfer of know-how, by way of the interactions with foreign businesses (Grossman and Helpman, 1991).

A substantial empirical literature reports evidence consistent with the ELG hypothesis, including: Mickaely (1977), Balassa (1978, 1985), Tyler (1981), Feder (1982), Ram (1987), Chow (1987) Giles et al. (1992), Thornton (1996), Doyle (1998), Xu (1996), Erfani (1999), Balaguer (2004), Shirazi (2004), Jordaan and Eita (2007) and Saad (2012). In the context of South Africa, Rangasamy (2009) used an error correction model (ECM) and found unidirectional Granger-causality from exports to GDP. Ziramba (2011) tested the hypothesis of export-led growth using the component of exports, based on the bounds testing approach, to reveal that only merchandise exports lead to growth.

In contrast with the ELG hypothesis, proponents of the GLE hypothesis have postulated that output growth promotes exports by means of enhanced productivity and reduced costs which arise from improvement in human capital and technology (Kaldor, 1967; Lancaster, 1980; Krugman, 1984). A substantial body of 
empirical support has also been reported in favour of this hypothesis, including: Granger (1969), Sims (1972), Jung and Marshall (1985), Shan and Tian (1998), Oxley (1993), Giles and Williams (2000), Safdari et al. (2011), Tang and Lai (2011), and Abbas (2012). In the South African literature, support for the GLE hypothesis can be found in Ukpolo (1998), and Dodaro's (1993) Granger causality based studies.

In addition to these contradictory hypotheses, there are a number of studies that fall in two additional categories: those that report bi-directional causality between exports and GDP, and those that report no evidence of causality between these variables. Amongst those who report evidence of bi-directional causality, we find: Kwan and Cotsomitis (1991), Amoateng and Amoako-adu (1996), Hatemi-J (2002), Mah (2005), Awokuse (2007), Awokuse and Christopoulos (2009), Jordaan and Eita (2009), Ray (2011), Balcilar and Ozdemir (2013) and Lim and Ho (2013). While Rangasamy's (2009) ECM based study reported evidence in support of the ELG hypothesis for South Africa, Bahmani-Oskooee and Alse's (1993) earlier use of the same method suggested that the causality might be bidirectional, which in turn has been recently corroborated by Cipamba Wa Cipamba (2013) who uses a (vector) ECM approach. Chang et al. (2013) examine the causal relationship between exports and GDP in nine provinces of South Africa using a panel Granger causality analysis and reported evidence of unidirectional causality, from GDP to exports for the province of Mpumalanga. They also find evidence of bi-directional causality between exports and GDP for the province of Gauteng; and no causality between GDP and exports for the rest of provinces.

This brings us to the part of the literature which finds no evidence of a causal relationship, including: Darrat (1986) ${ }^{1}$, Hsiao (1987) Ahmad and Kwan (1991) Jin and Yu, (1996) Ahmed et al. (2000), Ramos (2001) Ribeiro, (2001), Amavilah (2003), and Pazim (2009). For South Africa, Dutt and Ghosh (1996) found no evidence of a causal relationship with the use of the same ECM methodology that has been used to provide evidence of bidirectional causality in Bahmani-Oskooee and Alse, 1993. This methodology has also provided support for the ELG hypothesis in Rangasamy, 2009.

Methodological flaws could be one explanation for the often contradictory results in this literature, which include those for South Africa, besides other issues like variable definition, sample-period and data frequency. The causal connection between exports and GDP has typically been investigated with standard linear Granger causality test. Most economic time series exhibit structural breaks at one time or the other. Therefore, the relationship between a response variable and the explanatory variable(s) may not be constant or linear, throughout the duration of dataset. The classical Granger causality test is parametric, and used linear time series model for the conditional mean. However, tests based on residuals will be sensitive only to causality in the conditional mean while covariables may influence the conditional distribution of the response in nonlinear ways. In view of this, nonparametric techniques are appealing because they place direct emphasis on prediction without imposing a linear functional form. In addition, the nonlinear models provide a better fit than linear models, and are more appropriate when there are structural breaks and regime changes. In general, the linear approach to causality testing, have low power, when compared to nonlinear Granger causality tests (Baek and Brock, 1992). Hence, this motivates for a more flexible methodology that may account for possible nonlinearities. Therefore, in addition to linear Granger causality tests, we make use of two nonlinear causality tests, which include the Hiemstra and Jones (1994) and Diks and Panchenko (2006) procedures. Diks and Panchenko (2006) addressed a consistency problem in the Hiemstra and Jones (1994) 
nonparametric test for nonlinear Granger causality as they showed that the latter can over-reject if the null hypothesis of noncausality is true. Hence, we view Diks and Panchenko (2006) as more robust and powerful. The nonlinear causality statistic employed is nonparametric and does not assume any functional form. Therefore, it allows for more general dependence and complex nonlinear interaction between exports and the output series. The use of nonlinear approaches is, in turn, motivated by a wide array of tests of parameter (in-) stability, particularly within the presence of structural breaks. Furthermore, since we use the longest possible data set available on these two variables for South Africa, the decision to test for structural break is of great importance. To the best of our knowledge, this is the first paper to not only use over a century of data to test the causal relationship between exports and growth for South Africa, but it is also the first attempt at using both linear and nonlinear causality tests for this research question.

The remainder of the paper is organized as follows: section two describes the empirical model, whilst a discussion of the data and results is included in section three. Section four concludes.

\section{METHODOLOGY}

\section{Linear Granger Causality Testing}

Granger (1969) defines causality between two stationary series $x$ and $y$ in terms of predictability. Formally, a time series $y_{t}$ Granger-causes another time series $x_{t}$ if series $x_{t}$ can be predicted better by using past values of $y_{t}$ than by using only the historical values of $x_{t}$. Suppose $x_{t}$ and $y_{t}$ of length $n$ are exports and economic growth (GDP) respectively. Testing for causal relations between the two series involves estimating a $p$-order linear vector autoregressive model, $\operatorname{VAR}(p)$, as follows:

$$
\left[\begin{array}{l}
y_{t} \\
x_{t}
\end{array}\right]=\left[\begin{array}{l}
\alpha_{1} \\
\alpha_{2}
\end{array}\right]+\left[\begin{array}{ll}
\phi_{11,1} & \phi_{12,1} \\
\phi_{21,1} & \phi_{22,1}
\end{array}\right]\left[\begin{array}{l}
y_{t-1} \\
x_{t-1}
\end{array}\right]+\left[\begin{array}{ll}
\phi_{11, p} & \phi_{12, p} \\
\phi_{21, p} & \phi_{22, p}
\end{array}\right]\left[\begin{array}{l}
y_{t-p} \\
x_{t-p}
\end{array}\right]+\left[\begin{array}{l}
\varepsilon_{1 t} \\
\varepsilon_{2 t}
\end{array}\right]
$$

where ${ }_{t}=\left({ }_{1 t},{ }_{2 t}\right)$ is a white noise process with zero mean and covariance matrix $\Sigma$ and $p$ is the lag order of the process. In the empirical section, the sequential likelihood ratio $(L R)$ test is used to select the optimal lag order $p$. The $\alpha_{1}$ and $\alpha_{2}$ parameters are constants and the $\phi^{\prime} s$ are coefficients. In this setting, the null hypothesis that exports do not Granger cause GDP can be tested by imposing the restrictions that $\phi_{12, i}=0$ for $i=1,2, \ldots, p$. In other words, this test may be used to investigate whether exports contain predictive or causal content for the measure of GDP. Hence, we conclude that there is evidence of Granger causality if we are able to reject the joint zero restrictions under the null hypothesis:

$$
H_{0}^{E}: \phi_{12,1}=\phi_{12,2}=\ldots=\phi_{12, p}=0
$$

Analogously, the null hypothesis that GDP does not Granger cause exports implies that we can impose zero restrictions $\phi_{21, i}=0$ for $i=1,2, \ldots, p$. In this case, GDP does not contain predictive content when explaining the behaviour of exports. Hence, the joint zero restrictions for the null hypothesis that there is no Granger causality, are: 


$$
H_{0}^{G}: \phi_{21,1}=\phi_{21,2}=\ldots=\phi_{21, p}=0
$$

The Granger causality tests in equations (2) and (3) can be linked to the ELG and GLE hypotheses as follows. If the hypothesis in Eq. (2) is rejected, then exports Granger causes GDP. This establishes evidence in favour of the ELG hypothesis. Analogously, if the hypothesis in Eq. (3) is rejected, GDP Granger causes exports. This establishes evidence in favour of the GLE hypothesis. If it is the case that only one of these conditions holds, then we have the case of unidirectional causality. However, where both hypotheses in Eq. (2) and Eq. (3) are rejected, then the evidence would suggest that there is bidirectional causality, which in this context implies a feedback system where exports and GDP react to each other. It is also possible that neither of these two hypotheses are rejected, implying that neither of the two variables has predictive content, when describing the behaviour of the other.

\section{Parameter Stability Test}

Linear Granger non-causality tests assume that parameters of the VAR model are constant over time. This assumption is often violated, when the parameters are subject to structural changes. As Granger (1996) pointed out, parameter nonconstancy is one of the most challenging issues confronting empirical studies. Hence, we test for the stability of the parameters of the VAR, on the growth rates of the variables, as both the standard linear and the nonlinear Granger causality tests require that the variables are stationary.

In practice, a number of tests may be used for examining the temporal stability of VAR models (e.g. Hansen, 1992; Andrews, 1993; Andrews and Ploberger, 1994). These tests can be applied in a straightforward manner to stationary models. In particular, we use the Sup- $F$, Ave- $F$ and Exp- $F$ tests developed by Andrews (1993) and Andrews and Ploberger (1994), to investigate the stability of the short-run parameters. However, if the variables are cointegrated when measured in their levels, then the model in first differences is mispecified (unless it allows for an error-correction mechanism). Therefore, we also include tests for cointegration and the stability of the long-run relationship. This is done based on different structural break and parameter stability tests on the long-run relationship, estimated using the fully modified ordinary least squares (FM-OLS) estimator of Phillips and Hansen (1990). When investigating the long-run relationship, we use the $L_{c}$ tests of Nyblom (1989) and Hansen (1992). If the series are I(1), the Nyblom-Hansen $L_{c}$ test would also serve as a test of cointegration (Balcilar et al., 2010). In addition, we also use the Sup- $F$, Ave-F and Exp-F tests to determine whether the long-run relationship is stable.

These tests are computed from the sequence of $L R$ statistics that test for constant parameters against the alternative of a one-time structural change at each possible point of time (over the full sample). Andrews (1993) and Andrews and Ploberger (1994) report the critical values for the non-standard asymptotic distributions of these tests. To avoid the use of asymptotic distributions, the critical values and $p$-values are obtained using the parametric bootstrap procedure. Specifically, the $p$-values are obtained from a bootstrap approximation to the null distribution of the test statistics, constructed by means of Monte Carlo simulation using 2000 samples generated from a VAR model with constant parameters. The Sup- $F$, Ave- $F$ and Exp- $F$ tests needs to be trimmed at the ends of the sample. Following Andrews (1993), we trim 15 percent of the sample, from both ends and 
calculate these tests for the fraction of the remaining sample between the interval $[0.15,0.85]$.

\section{Nonlinear Granger Causality Testing}

While the linear approach is appealing due to its simplicity, the test has some limitations. As a parametric test, it relies on relatively strong assumptions about the underlying data, the most important of which is that the relationships within the regression structure are linear. However, it is now widely recognized that most economic and financial data are characterized by nonlinear features that may arise from structural breaks (as well as other phenomena). Furthermore, whilst many have tested for nonlinearity in the conditional mean, before performing a Granger causality test, this practice may not be sufficient to detect nonlinear effects on the conditional distribution (Baek and Brock, 1992). Higher order nonlinearities, such as conditional heretoskedasticity, is also often ignored (Diks and Panchenko, 2005, 2006) and traditional linear Granger causality test have low power in the presence of these nonlinear relations (Hiemstra and Jones, 1994). In view of these findings, nonparametric approaches are appealing, since they place direct emphasis on prediction without imposing the assumption that the underlying data maintains a specific functional form. Various nonparametric tests have been proposed in the literature, and one of the most prominent of these tests was developed by Hiemstra and Jones (1994), which has been modified by Baek and Brock (1992). An alternative nonlinear model was proposed by Diks and Panchenko $(2005,2006)$ who show that the relationship tested by Hiemstra and Jones (1994) is not generally compatible with Granger causality, as it would lead to the over rejection of the null hypothesis of noncausality. To ensure that the results are not susceptible to these critiques, we use the procedures of both Hiemstra-Jones (1994) and Diks-Panchenko (2006) in the subsequent analysis.

\section{Hiemstra-Jones Nonlinear Causality Test}

Hiemstra and Jones (1994) proposed a nonparametric statistical method for detecting nonlinear causal relationships, based on the correlation integrals. To define nonlinear Granger causality, assume that there are two strictly and weakly dependent time series $\left\{X_{t}\right\}$ and $\left\{Y_{t}\right\}, t=1,2,3, \ldots, T$. Let the $m$-length lead vector of $X_{t}$ be designated by $\mathbf{X}_{t}^{m}$, and denote the $L x$-length and $L y$-length lag vectors of $X_{t}$ and $Y_{t}$, with the notation $\mathbf{X}_{t-L x}^{L x}$ and $\mathbf{Y}_{t-L y}^{L y}$, respectively. For given values of $m, L x$ and $L y \geq 1$ and for all $e>0,\left\{Y_{t}\right\}$ does not strictly Granger cause $\left\{X_{t}\right\}$ if: ${ }^{2}$

$$
\begin{aligned}
& P\left(\left\|\mathbf{X}_{t}^{m}-\mathbf{X}_{s}^{m}\right\|<e\left\|\mathbf{X}_{t-L x}^{L x}-\mathbf{X}_{s-L x}^{L x}\right\|<e,\left\|\mathbf{Y}_{t-L y}^{L y}-\mathbf{Y}_{s-L y}^{L y}\right\|<e\right) \\
& =P\left(\left\|\mathbf{X}_{t}^{m}-\mathbf{X}_{s}^{m}\right\|<e\left\|\mathbf{X}_{t-L x}^{L x}-\mathbf{X}_{s-L x}^{L x}\right\|<e\right),
\end{aligned}
$$

where $P(\cdot)$ denotes probability; \|\|$\|$ denotes the maximum norm and $e$ is the length scale. The probability on the LHS of Eq. (4) is the conditional probability that two arbitrary $m$-length lead vectors of $\left\{X_{t}\right\}$ are within distance $e$ of each other, given that the corresponding $L x$-length lag vectors of $\left\{X_{t}\right\}$ and $L y$-length lag vectors of $\left\{Y_{t}\right\}$ are within a distance $e$ of each other. The probability on the RHS of Eq. (4) is the conditional probability that two arbitrary m-length lead vectors of $\left\{X_{t}\right\}$ are within 
a distance $e$ of each other, given that their corresponding Lx-length lag vectors are within a distance $e$ of each other.

A test based on Eq. (4) can be implemented by expressing the conditional probabilities in terms of the corresponding ratios of joint probabilities:

$$
\frac{C 1(m+L x, L y, e)}{C 2(L x, L y, e)}=\frac{C 3(m+L x, e)}{C 4(L x, e)}
$$

where $C 1, C 2, C 3$ and $C 4$ refer to the correlation integral estimators of the joint probabilities, which are discussed in detail by Hiemstra and Jones (1994). With an additional index $n$, Hiemstra and Jones (1994) show that, under the assumptions that $\left\{X_{t}\right\}$ and $\left\{Y_{t}\right\}$ are strictly stationary weakly dependent, and satisfy the mixing conditions, if $\left\{Y_{t}\right\}$ does not strictly Granger cause $\left\{X_{t}\right\}$, then the test statistics (i.e. the product of $\sqrt{n}$ and the ratio difference of correlation-integral estimators) has a normal distribution:

$$
\begin{aligned}
& \sqrt{n}\left(\frac{C 1(m+L x, L y, e, n)}{C 2(L x, L y, e, n)}\right)-\left(\frac{C 3(m+L x, e, n)}{C 4(L x, e, n)}\right) \\
& \stackrel{a}{\sim} N\left(0, \sigma^{2}(m, L x, L y, e)\right)
\end{aligned}
$$

where $n=T+1-m-\max (L x, L y)$. See the appendix of Hiemstra and Jones (1994) for further details of the estimation of $\sigma^{2}(m, L x, L y, e)$. For evaluation purposes, one-sided (right-tailed) critical values are used, based on this asymptotic result. Therefore, one would reject the null hypothesis when the observed value of the test statistic in Eq. (6) is too large.

To test for nonlinear Granger causality between $\left\{X_{t}\right\}$ and $\left\{Y_{t}\right\}$, the test in Eq. (6) is applied to the estimated residual series from the bivariate VAR model. The null hypothesis is that $Y_{t}$ does not strictly Granger cause $X_{t}$, through any nonlinear relationship, and Eq. (6) holds for all $m, L x, L y \geq 1$ and $e>0$. By removing the linear predictive power in a linear VAR model, any remaining incremental predictive power of one residual series can be used to describe the nonlinear predictive power (Baek and Brock, 1992).

\section{Diks-Panchenko Nonlinear Causality Test}

Diks and Panchenko $(2005,2006)$ argue that their test reduces the risk of over rejection of the null hypothesis of non-causality, observed in the Hiemstra and Jones (1994). The method of Diks and Panchenko (2006) introduced a new nonparametric test for Granger non-causality, which avoids the over rejection, by replacing the global test statistic with an average of local conditional dependence measures. On the basis of these arguments, we employ both Hiemstra and Jones (1994) and Diks and Panchenko (2006) nonlinear Granger causality tests in this study. 
Suppose that $X_{t}^{l_{X}}=\left(\mathrm{X}_{\mathrm{t}-\ell} X^{+1}, \ldots, \mathrm{X}_{\mathrm{t}}\right)$ and $Y_{t}^{l_{Y}}=\left(\mathrm{Y}_{\mathrm{t}-\ell} Y^{+1}, \ldots, \mathrm{Y}_{\mathrm{t}}\right)$ are the delay vectors, where $\ell_{X}, \ell_{\mathrm{Y}} \geq 1$. The null hypothesis that $X_{t}^{l_{X}}$ contains additional information about $Y_{t+1}$ is specified as:

$$
H_{0}=Y_{t+1}\left|\left(X_{t}^{l_{x}} ; Y_{t}^{l_{Y}}\right) \sim Y_{t+1}\right| Y_{t}^{l_{Y}}
$$

The null hypothesis becomes a statement about the invariant distribution of the $\left(\ell_{X}+\ell_{Y}+1\right)$ dimensional vector, $\mathrm{W}_{\mathrm{t}}=\left(X_{t}^{l_{X}}, Y_{t}^{l_{X}}, Z_{t}\right)$, where $\mathrm{Z}_{\mathrm{t}}=\mathrm{Y}_{\mathrm{t}+1}$. If we ignore the time index and we assume that $\ell_{X}=\ell_{Y}=1$, then the distribution of $Z$, given that $(X, Y)=(x, y)$, is the same as that of $Z$, given $Y=y$. In other words, $X$ and $\mathrm{Z}$ are independent conditionally on $\mathrm{Y}=\mathrm{y}$, for each fixed value of $\mathrm{y}$, so the joint probability density function $\mathrm{f}_{\mathrm{X}, \mathrm{Y}, \mathrm{Z}}(\mathrm{x}, \mathrm{y}, \mathrm{Z})$ and its marginals must satisfy the following relationship:

$$
\frac{f_{X, Y, Z}(x, y, z)}{f_{Y}(y)}=\frac{f_{X, Y}(x, y)}{f_{Y}(y)} \cdot \frac{f_{X, Z}(y, z)}{f_{Y}(y)}
$$

Diks and Panchenko (2006) show that the restated null hypothesis implies:

$$
q \equiv E\left[f_{X, Y, Z}(X, Y, Z) f_{Y}(Y)-f_{X, Y}(X, Y) f_{Y, Z}(Y, Z)\right]=0
$$

where $\hat{f}_{\mathrm{w}}\left(\mathrm{W}_{\mathrm{i}}\right)$ is a local density estimator of a $\mathrm{d}_{\mathrm{W}}$-variate random vector $\mathrm{W}$ at $\mathrm{W}_{\mathrm{i}}$,

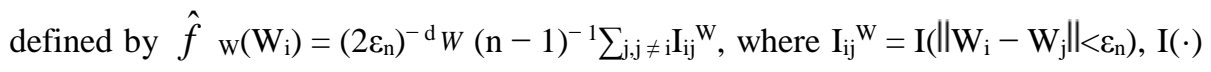
the indicator function and $\varepsilon_{\mathrm{n}}$ the bandwidth, which depends on the sample size $n$. simplified as:

The test statistic, which is a scaled sample version of $q$ in equation (9), is

$$
\left.T_{n}\left(\varepsilon_{n}\right)=\frac{n-1}{n(n-2)} \cdot \sum_{i}-\hat{f}_{X, Y}\left(\hat{f}_{X, Z, Y}, Y_{i}\right) \hat{f}_{Y, Z}\left(Y_{i}, Z_{i}\right)\right)
$$

where $T_{n}$ consists of a weighted average of local contributions $\hat{f}_{X, Z, Y}\left(X_{i}, Z_{i}, Y_{i}\right) \hat{f}_{Y}\left(Y_{i}\right)-\hat{f}_{X, Y}\left(X_{i}, Y_{i}\right) \hat{f}_{Y, Z}\left(Y_{i}, Z_{i}\right)$, which tend to zero in probability under the null hypothesis.

Diks and Panchenko (2006) provide a proof which states that if $\varepsilon_{n}=C n^{-\beta}\left(C>0, \frac{1}{4}<\beta<\frac{1}{3}\right)$ for one lag, then the test statistic in equation (10) satisfies the following condition:

$$
\sqrt{n} \frac{\left(T_{n}\left(\varepsilon_{n}\right)-q\right)}{S_{n}} \stackrel{D}{\longrightarrow} N(0,1)
$$


where $\stackrel{D}{\longrightarrow}$ denotes convergence in distribution and $S_{\mathrm{n}}$ is an estimator of the asymptotic variance of $T_{n}(\cdot)$.

\section{DATA AND EMPIRICAL RESULTS}

This study used annual data on real exports and real Gross Domestic Product (GDP) for South Africa, from 1911 to 2011. This data was obtained from the Global Financial Database. The measure of GDP is at constant 2005 prices, as measured in terms of the local currency. The exports data was originally obtained in nominal dollar value terms. We used the rand-dollar exchange rate to convert it into the nominal terms of the domestic currency, and then used the consumer price index (with a base year of 2005) to deflate the nominal rand value of exports. This provides a measure of real exports in constant 2005 prices, as measured by the local currency.

The Union of South Africa was formed in 1910, to establish a country that occupies the same geographical area as it does currently. Any earlier starting point for national data would be problematic as this would relate to a country of a different geographic area. The end-point of the dataset is the final data point that was available at the time of writing. The plot of the growth rates of the two series is shown in Figure 1. The scale on the left axis pertains to export growth, while the scale on the right axis pertains to GDP growth. Note that there appears to be strong comovement between exports and GDP. However, whether this comovement relates to causation will be verified using the relevant tests.

FIGURE 1. GROWTH RATES OF REAL EXPORTS (LEFT VERTICAL SCALE) AND REAL GDP (RIGHT VERTICAL SCALE)

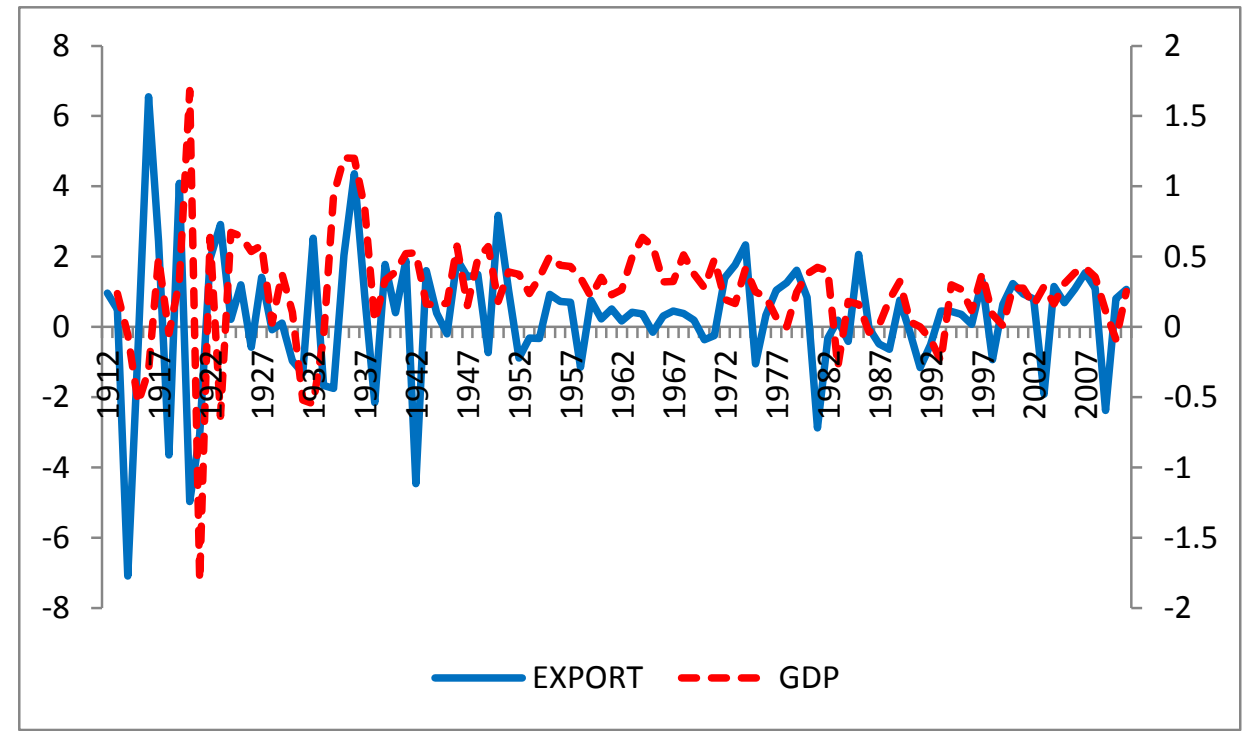


Prior to investigating Granger causality, we test for the stationarity of the data using the $Z_{\alpha}$ unit root test of Phillips (1987) and Philips and Perron (1988) (PP). In addition, we also use the Augmented Dickey Fuller (ADF) test and the $M Z_{\alpha}$ test of $\mathrm{Ng}$ and Perron (2001). ${ }^{3}$ Table 1 reports the results of the unit root tests for exports and GDP, using two specifications ${ }^{4}$ reported for each of the three tests.

\section{TABLE 1. UNIT ROOT TESTS}

\section{Panel A. Level}

\begin{tabular}{|c|c|c|c|c|c|c|}
\hline \multirow[t]{2}{*}{ Series } & \multicolumn{2}{|l|}{$A D F$} & \multicolumn{2}{|l|}{$P P$} & \multicolumn{2}{|l|}{$N P$} \\
\hline & constant & $\begin{array}{l}\text { Constant } \\
\text { and trend }\end{array}$ & constant & $\begin{array}{l}\text { Constant } \\
\text { and trend }\end{array}$ & Constant & $\begin{array}{l}\text { Constant } \\
\text { and trend }\end{array}$ \\
\hline GDP & -0.286 & -1.455 & -0.268 & -1.529 & 1.514 & -3.612 \\
\hline Exports & -0.381 & $-4.585 * * *$ & 0.305 & $-4.475 * * *$ & 1.097 & $-19.258 * *$ \\
\hline \multicolumn{7}{|c|}{ Panel B. First difference } \\
\hline \multirow[t]{2}{*}{ Series } & $A D F$ & & $P P$ & & $N P$ & \\
\hline & constant & $\begin{array}{l}\text { Constant } \\
\text { and trend }\end{array}$ & constant & $\begin{array}{l}\text { Constant } \\
\text { and trend }\end{array}$ & constant & $\begin{array}{l}\text { Constant } \\
\text { and trend }\end{array}$ \\
\hline GDP & $-9.537 * * *$ & $-9.488 * * *$ & $-9.536^{* * *}$ & $-9.487 * * *$ & $-49.422 * * *$ & $-49.441 * * *$ \\
\hline Exports & $-10.798 * * *$ & $\begin{array}{l}- \\
10.779 * * *\end{array}$ & $\begin{array}{l}- \\
13.841 * * *\end{array}$ & $\begin{array}{l}- \\
14.017 * * *\end{array}$ & $-49.428 * * *$ & $-49.209 * * *$ \\
\hline
\end{tabular}

Notes: *, **, and *** denote significance at 10\%, 5\%, and 1\%, respectively.

The null hypothesis in these tests is that the series are non-stationary (i.e. they have a unit root) and the tests are performed for the levels (Panel A in Table 1) and the first differences (Panel B) of the data. GDP appears to be integrated of the first order, I(1), as is evidenced in Table 1, where the null hypothesis is not rejected at conventional critical values for the series in levels. This null is however rejected in Panel B, where the data has been transformed into first differences. For the exports data, when we allow for intercept only, the null hypothesis could not be rejected. However, after allowing for both intercept and trend, the null hypothesis is rejected in all three tests. Given that the exports data in levels (see Figure A1. in the Appendix) did not appear to have a deterministic trend, we conclude that the series is nonstationary and hence integrated of the first order, I(1).

Following these preliminaries, the study now proceeds with the investigation of the causal connection between exports and GDP in South Africa (with linear and nonlinear models) using the first differences of the two series. The two null hypotheses at stake are (a) that exports do not Granger cause GDP and (b) that GDP does not Granger cause exports. The results from the linear Granger causality are presented in Table 2 . The optimal lag length as selected by sequential $L R$ test is three, for the variables in their log-levels. Hence, we implement a stable VAR (2) model (where all the roots lie inside the unit circle) for the variables in their first differences. Both hypotheses cannot be rejected at any of the conventional level 
of significance. Combining these two results suggests the absence of causality between exports and GDP.

\section{TABLE 2. RESULTS FROM LINEAR GRANGER CAUSALITY TEST}

$\begin{array}{lc}\text { Hypothesis } & p \text {-value } \\ \mathrm{H}_{0}: \text { Exports } \neq>\text { GDP } & 0.3470 \\ \mathrm{H}_{0}: \mathrm{GDP} \neq>\text { Exports } & 0.5061\end{array}$

Note: This table reports the p-values.

At this point, we investigate the stability of the estimated VAR. The parameter constancy tests described above were used to test for parameter stability in the model for the causality tests reported in Table 2 . Three different tests of short-run parameter stability are reported in Table 3 . The second and third columns relate to the exports equation and the GDP equation, respectively, while the fourth column relates to the overall VAR system. The Sup-F statistic reports on the test of parameter constancy against a one-time sharp shift in parameters. This is followed by the Ave-F and Exp-F test statistics, which assume that the parameters follow a martingale process. Therefore, they test the possibility that the parameters might only evolve gradually. ${ }^{5}$ All three tests suggest that there may be evidence of short-run parameter instability in the GDP equation. However, there is evidence in favour of short-run parameter stability in the exports equation. It is also worth noting that the Sup-F and $\operatorname{Exp}-F$ tests suggest that there is evidence of parameter instability in the VAR as a whole. The evidence in Table 3 suggests both one-time shifts, as well as a gradual evolution of the parameters in the exports-GDP VAR.

\section{TABLE 3. PARAMETER STABILITY TESTS}

\begin{tabular}{llllll} 
Exports Equation & \multicolumn{2}{l}{ GDP Equation } & VAR (2) System \\
Statistics & $\begin{array}{l}\text { Bootstrap } \\
p \text {-value }^{\mathrm{a}}\end{array}$ & Statistics & $\begin{array}{l}\text { Bootstrap } \\
p \text {-value }^{\mathrm{a}}\end{array}$ & Statistics & $\begin{array}{l}\text { Bootstrap } \\
p \text {-value }^{\mathrm{a}}\end{array}$ \\
10.29 & 0.52 & 21.15 & 0.02 & 39.16 & 0.01 \\
4.01 & 0.64 & 9.41 & 0.04 & 9.46 & 0.52 \\
3.19 & 0.44 & 7.65 & 0.01 & 16.35 & $<0.01$
\end{tabular}

Notes: *,**, and *** denote significance at 10, 5 and 1 percent, respectively. ${ }^{a}$-values are calculated using 2000 bootstrap repetitions. 
If cointegration exists, then the model in first differences is misspecified. Therefore, we also estimated the cointegration equation between real exports and real GDP, as follows:

$$
G D P_{t}=\alpha+\beta \cdot E X P O R T_{t}+\varepsilon_{t}
$$

We estimate the parameters in equation (14) using the FM-OLS estimator. Table 4 reports the results of the various parameter stability tests. The Nyblom-Hansen $L_{c}$ test rejects the null hypothesis of cointegration at $1 \%$ level. Similarly, the Sup-F, Ave-F and $\operatorname{Exp}-F$ tests reject the null hypothesis of unchanging parameters in the cointegration equation. In other words, we find evidence of both one-time shift and gradual shifting of the parameters in the cointegration equation (which would suggest that constant linear cointegrating relationship does not exist). Hence, we reject the postulate that the variables are cointegrated,${ }^{6}$ where there is evidence of structural break. In other words, our model specification with the first difference growth rate is not misspecified.

\section{TABLE 4. PARAMETER STABILITY TESTS IN LONG-RUN RELATIONSHIP}

$\begin{array}{lllll} & \text { Sup }-\boldsymbol{F} & \text { Ave-F } & \text { Exp-F } & \boldsymbol{L}_{\boldsymbol{c}} \\ \text { GDP }=\boldsymbol{\alpha}+\boldsymbol{\beta} * \text { EXPORTS } & 71.63 & 29.23 & 32.22 & 2.26 \\ \text { Bootstrap } \boldsymbol{p} \text { value } & <0.01 & <0.01 & <0.01 & 0.01\end{array}$

Notes: We calculate p-value using 2,000 bootstrap repetitions.

Note also that parameter instability of the kind identified here would undermine the traditional linear Granger causality test that describes the connection between exports and GDP. One would expect that the Granger causality tests would be sensitive to structural changes in this case and it might help to explain why studies have found conflicting evidence on the causal nature of the relationship for the same country.

Accordingly, we proceed to investigate the association between exports and GDP with nonlinear Granger causality tests. Table 5 reports the results from Hiemstra and Jones (1994) nonlinear Granger causality test, based on the residual from the bivariate VAR. Following Hiemstra and Jones (1994), we set the value for the lead length, $m=1$, the common lag lengths $(L x=L y)$, from 1 to 8 , and a common scale parameter of $e=1.5 \sigma$, where $\sigma=1$ denotes the standard deviation of the standardized time series test statistic. The results in Table 5 indicate that the null hypothesis, that exports do not Granger cause GDP, cannot be rejected at any at reasonable significance level. However, the null hypothesis that GDP does not Granger cause exports is rejected at 5 percent level; but only at 7 and 8 lags. Hence, the Hiemstra and Jones (1994) test provides evidence in favour of the GLE hypothesis only. 
TABLE 5. HIEMSTRA AND JONES (1994) NONLINEAR CAUSALITY TEST

\begin{tabular}{llllll}
\multicolumn{2}{c}{$\mathrm{H}_{0}:$ Exports $\neq>$ GDP } & & \multicolumn{2}{l}{$\mathrm{H}_{0}:$ GDP $\neq>$ Exports } \\
Lags & $\mathrm{CS}$ & TVAL & Lags & CS & TVAL \\
1 & -0.3647 & -3.4599 & 1 & -0.4151 & -3.9385 \\
2 & -0.1657 & -1.5719 & 2 & -0.3393 & -3.2194 \\
3 & -0.0197 & -0.1872 & 3 & -0.3245 & -3.0785 \\
4 & -0.0624 & -0.5928 & 4 & -0.5180 & -4.9148 \\
5 & -0.2036 & -1.9318 & 5 & -0.7558 & -7.1705 \\
6 & -0.4608 & -4.3720 & 6 & -1.9648 & -18.6403 \\
7 & -0.7883 & -7.4788 & 7 & 0.6673 & $6.3310^{\mathrm{a}}$ \\
8 & -0.6533 & -6.1982 & 8 & 0.8975 & $8.5151^{\mathrm{a}}$
\end{tabular}

Notes: CS and TVAL are respectively the difference between the two conditional probabilities, and the standardized test statistic. "Lags" denote the number of lags in the residual series used in the test. ${ }^{a}$ indicates the rejection of the null hypothesis for the absence of causality at the $5 \%$ level.

Turning now to the results from the Diks and Panchenko (2006) nonlinear Granger causality test, which are reported in Table 6 . These results suggest that at the first lag, there is a bi-directional causality between exports and GDP at 5 percent level of significance. This implies that both the ELG and GLE hypotheses are supported. ${ }^{7}$

Overall, these findings point to the fact that using the standard linear Granger causality tests, which do not account for structural breaks and nonlinearities in the relationship between economic variables, may be misleading. Thus, unravelling the nonlinearities in the exports-GDP causal nexus is critical for proper policy conclusions. Based on the results from the Diks and Panchenko (2006) nonlinear tests, which is an improved and more robust version of the Hiemstra and Jones (1994) test, exports performed a growth-boosting function in South Africa, and GDP also served as a catalyst for exports expansion. 
TABLE 6. DIKS AND PANCHENKO (2005) NONLINEAR CAUSALITY TEST

$\begin{array}{lll}L x=L y & \mathrm{H}_{0}: \text { Exports } \neq>\text { GDP } & \mathrm{H}_{0}: \mathrm{GDP} \neq>\text { Exports } \\ 1 & 0.0324^{\mathrm{b}} & 0.0119^{\mathrm{b}} \\ 2 & 0.1654 & 0.1727 \\ 3 & 0.1444 & 0.2135 \\ 4 & 0.3899 & 0.4644 \\ 5 & 0.6699 & 0.5929 \\ 6 & 0.6638 & 0.3256 \\ 7 & 0.4752 & 0.2742 \\ 8 & 0.3136 & 0.1997\end{array}$

Notes: This Table reports the p-values of the Diks-Panchenko causality tests. ${ }^{b}$ indicates the rejection of the null hypothesis of absence of causality at the $5 \%$ level.

\section{CONCLUSION}

This paper contributes to the growing literature on the exports-economic growth relationship. We re-investigate the case for South Africa using annual data on real exports and real Gross Domestic Product from 1911-2011. By contrast to previous studies on the dynamic relationship between exports and GDP, this study uses both linear and nonlinear Granger causality tests. We employ both Hiemstra and Jones (1994) and Diks and Panchenko (2006) nonlinear tests that account for the existence of nonlinearities often evidenced among economic relationships due at times to structural changes. Based on the results of the linear Granger causality test, exports have no predictive power when seeking to describe GDP; and GDP also has no predictive power when seeking to describe exports.

However, the use of parameter stability tests suggest that the estimated VAR is unstable, which would undermine the inference that is drawn from linear Granger causality tests. Using the Hiemstra and Jones (1994) test, we show that at the 5 percent level of significance, there is a unidirectional causality running from GDP to exports. In other words, GDP has positive predictive power for exports but not vice versa. As Hiemstra and Jones (1994) test has been critiqued for not been generally compatible with Granger causality leading to the over rejection of the null hypothesis of noncausality, we also employ a more robust nonlinear causality test, the Diks and Panchenko (2006) test, and find a bi-directional causality between exports and GDP. This finding supports both the ELG and GLE hypotheses for the case of South Africa. These results indicate that the causal relation between exports and GDP is episodic and nonlinear. Since the more robust nonlinear tests, Diks and Panchenko (2006), indicate bidirectional causality, South Africa can expand its domestic market by exporting more both in terms of volume and diversified goods and services. As exports increase, it will contribute to overall growth in GDP by means of 
employment and income in the exports sector. Besides, exports operations may enable firms to pave the way for entering the foreign market and gain competitive advantages through increased local relations and mastering the technical knowledge in the long term (Helpman and Krugman, 1985). Exports in South Africa can also be promoted by increasing economic growth through enhanced human capital and technology development. Existence of nonlinearity in the relationship between export and GDP points to the fact that policy makers and government agencies need to be alert to the sensitivity of GDP to the changes in export and vice versa. Since the causal relationship may vary from time to time, a reality check is required accordingly to ensure that resources are efficiently allocated for greater trade, technological transfer, innovation and productivity. Given the slight difference in the results from the two nonlinear tests, researchers are recommended to model the inherent nonlinearities in the relationship between economic series using more powerful nonlinear models for cases where linear procedures are not appropriate.

\section{APPENDIX}

FIGURE A1. NATURAL LOGARITHMS OF REAL EXPORTS (LEXPORT) AND NATURAL LOGARITHMS OF REAL GDP (LGDP)

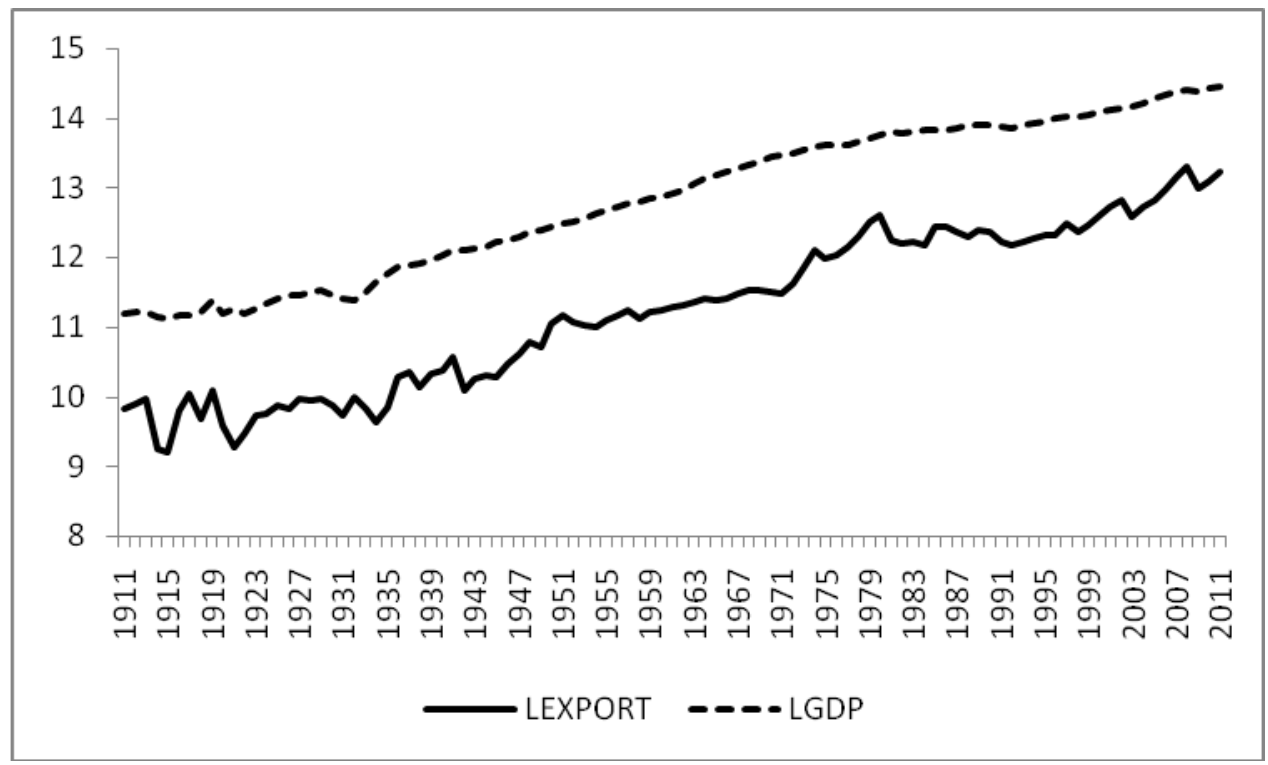




\section{ENDNOTES}

* We would like to thank an anonymous referee for many helpful comments. However, any remaining errors are solely ours.

${ }^{1}$ No causality was found from exports to economic growth in any of the four Asian countries (Hong Kong, South Korea, Singapore, and Taiwan) that were considered in this study. However, unidirectional causality was found running from economic growth to exports for Taiwan.

${ }^{2}$ Strict Granger causality relates to the past of one time series influencing the present and future of another time series (Hiemstra and Jones, 1994).

${ }^{3}$ The $Z_{\alpha}$ and $M Z_{\alpha}$ tests statistics have nonstandard distributions, and critical values are available from a number of sources. We used the response surface critical values computed by Mackinnon (1996).

4 The specifications differ in terms of the deterministic components included in the autoregressive function. The first version of every test was conducted with only a constant included, while the second version included a time trend in addition to a constant.

${ }^{5}$ The Ave-F and Exp-F are both optimal tests, as shown by Andrews and Ploberger (1994).

${ }^{6}$ Interestingly, the Trace test and the Maximum Eigen-Value test statistics developed by Johansen (1991) indicated the existence of one cointegrating relationship. Given this, we tested for short- and long-run causality using a Vector error-correction model (VECM). The results suggested that there is still no short-run causality, but a long-run causality exists running from GDP to exports. However, given that there is strong evidence of structural break in the longrun relationship, we cannot rely on these results. Details of the VECM analysis are available upon request from the authors.

${ }^{7}$ Using the methodologies developed in Sato et al., (2007), we also implemented dynamic Granger causality test (i.e., we test whether the Granger causality between two time series is time-invariant or not), as well as time-varying Granger causality test (i.e., we test for one variable does not cause the other versus one variable causes the other at least at one point in time). Interestingly, we could not detect causality in any direction using these tests. These tests, being time-variant in nature often requires large number of data pointsthan used in this study, and hence, could be a possible explanation for the lack of causality. The details of these results are available upon request from the authors.

\section{REFERENCES}

Abbas, S., "Causality between exports and economic growth: Investigating suitable trade policy for Pakistan", 2012, Eurasian Journal of Business and Economics, Vol. 5, No. 10, pp. 91-98. 
Ahmad, J. and Kwan, A.C., "Causality between exports and economic growth: empirical evidence from Africa”, 1991, Economics Letters, Vol. 37, No.3, 243-248.

Ahmed, Q., Butt, M., Sabihuddin, M. and Shaista, A., "Economic growth, exports and external debt causality: The case of Asian countries", 2000, The Pakistan Development Review, Vol. 34, No. 4, pp. 591-608.

Amoateng, K. and Amoako-Adu, B., "Economic growth, exports and external debt causality: the case of African countries", 1996, Applied Economics, Vol. 28, No.1, pp. 21-27.

Andrews, D.W.K., "Tests for parameter instability and structural change with unknown change point", 1993, Econometrica, Vol. 61, No. 4, pp. 821-856.

Andrews, D.W.K. and Ploberger, W., "Optimal tests when a nuisance parameter is present only under the alternative", 1994, Econometrica, Vol. 62, No.6, pp. 1383-1414.

Awokuse, T. O., "Causality between exports, imports, and economic growth: Evidence from transition economies”, 2007, Economics Letters, Vol. 94, No.3, pp. 389-395.

Awokuse, T.O. and Christopoulos, D.K., "Nonlinear dynamics and the exports-output growth nexus", 2009, Economic Modelling, Vol. 26, No. 1, pp. 184190.

Baek, E. and Brock, W., "A general test for non-linear Granger causality: bivariate model", 1992, Iowa State University and University of Wisconsin, Madison Working Paper.

Balcilar, M. and Ozdemir, Z.A., "The exports-output growth nexus in Japan: a bootstrap rolling window approach", 2013, Empirical Economics, Vol. 44, No.2, pp. 639-660.

Balcilar, M., Ozdemir, Z.A. and Arslanturk, Y., "Economic growth and energy consumption causal nexus viewed through a bootstrap rolling window", 2010 Energy Economics, Vol. 32, No.6, pp. 1398-1410.

Balaguer, J. and Manuel C-J., "Structural change in exports and Economic growth: Cointegration and Causality analysis for Spain (1961-2000)", 2004, journal Applied Economics, Vol. 36, No. 5, pp. 473-477.

Balassa, B., "Exports and economic growth: further evidence", 1978, Journal of Development Economics, Vol. 5, No. 2, pp. 181-189.

Balassa, B., "Exports, policy choices, and economic growth in developing countries after the 1973 oil shock", 1985, Journal of Development Economics, Vol. 18 , No. 1, pp. 23-35.

Bahmani-Oskooee, M. and Alse, J., "Exports growth and economic growth: an application of cointegration and error correction modelling", 1993, Journal of Developing Areas, Vol. 27, No. 4, pp.535-542.

Bhagwati, J. and Srinivasan, T., "Trade policy and development. In: Dornbunsch R., and Frenkel J., editors, International economic policy: theory and evidence”, 1979, Johns Hopkins University Press, Baltimore, pp 1-35.

Chang, T., Simo-Kengne, B.D. and Gupta, R., "The Causal Relationship between Exports and Economic Growth in the Nine Provinces of South Africa: Evidence from Panel-Granger Causality Tests", 2013, Department of Economics, University of Pretoria, Working Paper: 2013-19.

Chenery H.B. and Strout, A. M., "Foreign assistance and economic development", 1966, American Economic Review, Vol. LVI, No. 4, Part I. 
Chow, P.C.Y., "Causality between exports growth and industrial performance: evidence from NICs", 1987, Journal of Development Economics, Vol. 26, No. 1, pp. 55-63.

Cipamba Wa Cipamba, P., "The export-output relationship in South Africa: An empirical investigation", 2013, Economic Research Southern Africa (ERSA) Working Paper No. 355.

De Wet, G. L., "The prognosis for growth and development in South Africa", 1995, South African Journal of Economics, Vol. 63, No. 4, pp. 473-488.

Diks, C.G.H. and Panchenko, V. "A note on the Hiemstra-Jones test for Granger noncausality, 2005", Studies in Nonlinear Dynamics and Econometrics, Vol. 9, No. 2, pp. 1-7.

Diks, C.G.H. and Panchenko, V., "A new statistic and practical guidelines for nonparametric Granger causality testing", 2006, Journal of Economic Dynamics and Control, Vol. 30, No.9-10, pp. 1647-1669.

Dodaro, S., "Exports and growth: A reconsideration of causality", 1993, Journal of Developing Areas, Vol. 27, No. 2, pp. 227-44.

Doyle, E., "Exports-output causality: the Irish case 1953-93", Atlantic Economic Journal", 1998, Vol. 26, No. 2, pp. 147-161.

Dutt, S.D. and Ghosh, D., "The exports growth-economic growth nexus: A causality analysis", 1996, Journal of Developing Areas, Vol. 30, No. 2 , pp. 167-82.

Erfani, G.R., "Exports and economic growth in developing countries", 1999, International Advances in Economic Research, Vol. 5, No.1, pp. 147-148.

Feder, G., "On exports and economic growth", 1982, Journal of Development Economics, Vol. 12, No. 1/2, pp. 59-73.

Giles, D.E.A., Giles, J.A. and McCann, E., "Causality, unit roots, and exports-led growth: the New Zealand experience", 1992, Journal of International Trade and Economic Development, Vol. 1, pp. 195-218.

Giles, J.A. and Williams, C.L., "Exports-led growth: A survey of the empirical literature and some non-causality results. Part1", 2000, The Journal of International Trade and Economic Development: An International and Comparative Review, Vol. 9, No. 3, pp. 261-337.

Greenaway, D. and Sapsford, D., "Exports, growth, and liberalisation: an evaluation”, 1994, Journal of Policy Modeling, Vol. 16, No. 2, pp. 165-186.

Granger, C.W.J., "Investigating causal relations by econometrics models and cross spectral methods", 1969, Econometrica, Vol. 37, No.3, pp. 424-438.

Granger, C.W.J., "Can we improve the perceived quality of economic forecasts?", 1996, Journal of Applied Econometrics, Vol. 11, No. 5, pp. 455-73.

Grossman, G.M. and Helpman, E., Innovation and Growth in the Global Economy, 1991, Cambridge, MA: MIT Press.

Hsiao, M.C.W., "Tests of causality and exogeniety between exports and economic growth: the case of the Asian NIC's", 1987, Journal of Economic Development, Vol. 12, No. 2, pp. 143-159.

Hansen, B.E., "Tests for parameter instability in regressions with I(1) processes" 1992, Journal of Business and Economic Statistics, Vol. 10, No.3, pp. 321-335.

Hatemi-J, A., "Exports performance and economic growth nexus in Japan: a bootstrap approach", 2002, Japan and World Economy, Vol. 14, No.1, pp. 25-33.

Helpman, E. and Krugman, P. Market Structure and Foreign Trade, 1985, Cambridge, MA: MIT Press. 
Hiemstra, C. and Jones, J.D., "Testing for linear and nonlinear Granger causality in the stock price-volume relation", 1994, Journal of Finance, Vol. 49, No. 5, pp. 1639-1664.

Jin, J.C. and Yu, E.S.H., "Exports-led growth and the US economy, another Look", 1996, Applied Economics Letters, Vol. 3, No. 5, pp. 341-344.

Johansen, S., "Estimation and hypothesis testing of cointegration vectors in Gaussian vector autoregressive models", 1991, Econometrica, Vol. 59, No. 6, pp. $1551-1580$.

Jordaan, A.C. and Eita, J.H., "Exports and economic growth in Namibia: A Granger causality analysis", 2007, South Africa Journal of Economics, Vol. 75, No. 3, 540-547.

Jordaan, A.C. and Eita, J.H., "Testing the exports-led growth hypothesis for Botswana: A causality analysis" 2009, Botswana Journal of Economics, Vol. 6, No. 10, pp. 2-14.

Jung, W.S. and Marshall, P.J., "Exports, growth and causality in developing countries" 1985, Journal of Development Economics, Vol. 18, No. 1, pp. 1-12.

Kaldor, N., Strategic Factors in Economic Development, 1967, New York State School of Industrial and Labour Relations, Ithaca, NY: Cornell University.

Krueger, A.O., Foreign Trade Regimes and Economic Development: Liberalisation Attempts and Consequences, 1978, Cambridge, MA: Ballinger.

Krueger A, "Trade policy as an input to development", 1980, American Economic Review, Vol. 70, No.2, pp. 188-292.

Krugman, P.R., "Import protection as exports promotion. In H. Kierzkowski, editor, Monopolistic Competition in International Trade", 1984, Oxford: Oxford University Press.

Kwan, C.C.C. and Cotsomitis, J.A., "Economic growth and the expanding sector: China: 1925-1985", 1991. International Economic Journal, Vol. 5, No. 1, pp. 105-117.

Lancaster, K., "Intra-industry trade under perfect monopolistic competition", 1980, Journal of International Economics, Vol. 10, No. 2, pp. 151175.

Lim, S. Y. and Ho, C. M., "Nonlinearity in ASEAN-5 exports-led growth model: Empirical evidence from nonparametric approach", 2013, Economic Modelling, Vol. 32, No.3, pp. 136-145.

Little, I., Scitovsky, T. and Scott, M., Industry and Trade in Some Developing Countries, 1970, London: Oxford University Press.

MacKinnon, J.G., "Numerical distribution functions for unit root and cointegration tests", 1996, Journal of Applied Econometrics, Vol. 11, No. 6, pp. 601618.

Mah, J. S,. "Exports expansion, economic growth and causality in China", 2005, Applied Economics Letters, Vol. 12, No. 2, pp. 105-07.

McKinnon, R., "Foreign exchange constraints in economic development and efficient aid allocation", 1964, Economic Journal, Vol. 74, No. 294, pp. 388409.

Medina-Smith, E., "Is the exports-led growth hypothesis valid for developing countries? A case study of Costa Rica", 2001, Policy Issues in International Trade and Commodities Studies Series No 7 UNCTAD, Geneva and New York.

$\mathrm{Ng}, \mathrm{S}$. and Perron, P., "Lag length selection and the construction of unit root tests with good size and power", 2001, Econometrica, Vol. 69, No.6, pp. 1519-1554. 
Nyblom J., "Testing for the constancy of parameters over time", 1989, Journal of the American Statistical Association, Vol. 84, No. 405, pp. 223-230.

Oxley, L., "Cointegration, causality and exports-led growth in Portugal, 1865 -1985”, 1993, Economic Letters, Vol. 43, No.2, pp. 163-166.

Pazim, K. H., "Panel data analysis of "exports-led" growth hypothesis in BIMP-EAGA Countries”, 2009, MPRA, paper No. 13264.

Phillips, P.C., "Time series regression with a unit root", 1987, Econometrica, Vol. 55, No. 2, pp. 277-302.

Phillips, P.C. and Perron, P., "Testing for a unit root in time series regression", 1988, Biometrika, Vol. 75, No. 2, pp. 335-346.

Phillips, P.C.B. and Hansen, B.E., "Statistical inference in instrumental variables regression with I(1) processes", 1990, Review of Economics Studies, Vol. 57, No.1, pp. 99-125.

Ram, R., "Exports and economic growth in developing countries: evidence from time series and cross-section data", 1987, Economic Development and Cultural Change, Vol. 36, No. 1, pp. 51-72.

Ramos, F. F., "Exports, imports, and economic growth in Portugal: evidence from causality and cointegration analysis", 2001, Economic Modelling, Vol. 18, No. 4, pp. 613-623.

Rangasamy, L., "Exports and economic growth: the case of South Africa", 2009, Journal of International Development, Vol. 21, No.5, pp. 603-617.

Ray, S., "A causality analysis on the empirical nexus between exports and economic growth: Evidence from India", 2011, International Affairs and Global Strategy, Vol. 1, pp. 24-38.

Ribeiro, R. and Francisco F., "Exports, imports, and economic growth in Portugal: evidence from causality and cointegration analysis", 2001, Economic Modeling, Vol. 18, No. 4, pp. 613-23.

Singer, H.W. and Gray, P., "Trade policy and growth of developing countries: some new data", 1988, World Development, Vol. 16, No.3, pp. 395-403.

Saad, W., "Causality between economic growth, exports, and external debt servicing: The case of Lebanon", 2012, International Journal of Economics and Finance, Vol. 4, No. 11, pp. 134-143.

Safdari, M., Mahmoodi, M. and Mahmoodi, E., "The causality relationship between exports and economic growth in Asian developing countries", 2011, American Journal of Scientific Research, Vol. 25, pp. 40-45.

Sato, J.R., Morettin, P.A., Arantes, P.R. and Amaro, J.E., "Wavelet based time-varying vector autoregressive modelling", 2007, Computational Statistics \& Data Analysis, Vol. 51, No.12, pp. 5847-5866.

Shan, J. and Tian, G.G., "Causality between exports and economic Growth: The empirical evidence from Shanghai. Australian Economic Papers", 1998, Vol. 37, No. 2, pp. 95-202.

Shirazi, N. S. and Manap, T.A.A., "Exports-led growth hypothesis: further econometric evidence from Pakistan", 2004,. Pakistan Development Review, Vol. 43, No. 4, pp. 563-79.

Sims, C., "Money, income and causality", 1972, American Economic Review, Vol. 62, No. 4, pp. 540-552.

Tang, C. F. and Lai, Y. W., "The stability of exports-led growth hypothesis: Evidence from Asia's Four Little Dragons”, 2011, MPRA Paper, No. 27962.

Thornton, J., "Cointegration, causality and exports-led growth in Mexico, 1895-1992”, 1996, Economics Letters, Vol. 50, No.3, pp. 413-416. 
Tyler, W.G., "Growth and exports expansion in developing countries: some empirical evidence", 1981, Journal of Development Economics, Vol. 9, No. 1, pp. 121-130.

Ukpolo, V., "Exports and economic growth in South Africa: Evidence from cointegration and Granger causality tests", 1998, African Economic and Business Review, Vol. 1, No. 1, pp. 1-5.

Williamson, J., "What Washington Means by Policy Reform. In. Williamson, J., editor, Latin American Adjustment: How Much Has Happened?", 1990, Washington, Institute for International Economics.

$\mathrm{Xu}, \mathrm{Z}$., "On the causality between exports growth and GDP growth: an empirical evidence", 1996, Review of International Economics, Vol. 4, No. 6, pp. $172-184$.

Ziramba, E., "Export-led growth in South Africa: Evidence from the composition of exports", 2011, Studies in Economics and Econometrics, Vol. 35, No. 1, pp. 1-13. 